\title{
ASYMPTOTICS FOR THE SOBOLEV TYPE EQUATIONS WITH PUMPING
}

\author{
JHON J. PÉREZ
}

Abstract. We consider the large time asymptotic behavior of solutions to the initial-boundary value problem

$$
\left\{\begin{array}{l}
\partial_{t}\left(u-u_{x x}\right)+(1+t)^{n} u u_{x}-u_{x x}=0, x \in \mathbb{R}, t>0 \\
u(0, x)=u_{0}(x), x \in \mathbb{R} \\
u(t, x) \rightarrow a_{ \pm}, x \rightarrow \pm \infty, t>0
\end{array}\right.
$$

where $n \in \mathbb{N}$. We find large time asymptotic formulas of solutions for three different cases 1) $a_{ \pm}= \pm 1$, 2) $\left.a_{ \pm}=\mp 1,3\right) a_{ \pm}=0$.

Mathematics subject classification (2010): 35Q35, 35Q51, 35B40.

Keywords and phrases: Sobolev type equations, large time asymptotic bahavior, rerafaction wave, shock wave.

\section{REFERENCES}

[1] V. Bisognin, On the asympototic behavior of the solutions of a nonlinear dispersive system of Benjamin-Bona-Mahony's type, Boll. Un. Mat. Ital. B 10 (1996), 99-128.

[2] J. L. BONA AND L. LUO, More results on the decay of solutions to nonlinear, dispersive wave equations, Discrete and Continuous Dynamical Systems 1 (1995), 151-193.

[3] A. CONSTANTIN AND J. ESCHER, Wave breaking for nonlinear nonlocal shallow water equations, Acta Math., 181:2 (1998), 229-243.

[4] E. Di Benedetto, Degenerate parabolic equations, Universitext, Springer-Verlag, New York 1993.

[5] A. Favini And A. Yagi, Differential equations in Banach spaces, Marcel Dekker, New York 1999.

[6] S. A. GABov, New problems of the mathematical theory of waves, Fizmatlit, Moscow 1998.

[7] N. Hayashi, P.I. Naumkin, E.I. Kaikina And I.A. Shishmarev, Asymptotics for Dissipative Non-linear Equations, Lectura Notes in Mathematics, 1884, Springer-Verlag, Berlin (2005), 557.

[8] E. I. KAIKINA, P. I. NAUMKIN AND I. A. SHISHMAREV, Large-time asymptotic behaviour of nonlinear Sobolev-type equations, Uspekhi Mat. Nauk, 64:3 (387) (2009), 3-72; English transl.: Russian Math. Surveys, 64: 3 (2009), 399-468.

[9] E. I. Kaikina, P. I. NAum Kin AND I. A. Shishmarev, Asimptotic for a of Sobolev type equation with a critical nonlinearity, Differ. Equ. 43:5 (2007), 673-687.

[10] E. I. Kaikina, P. I. Naumkin And I. A. Shishmarev, The Cauchy problem for an equation of Sobolev type with power non-linearity, Izv. Math. 69:1 (2005), 59-111.

[11] M. Mei And C. SchmeIser, Asymptotic pro...les of solutions for the BBM-Burgers equations, Funkcial. Ekvac. 44 (2001), 151-170.

[12] P.I. NAUMKIN AND I.A. ShishmaReV, Nonlinear nonlocal equations in the theory of waves, Translations of monograhs, 133 A.M.S., Providence, R.I., 1994.

[13] R. Prado AND E. Zuazua, Asymptotic expansion for the generalized Benjamin-Bona-MahonyBurgers equation, J. Differential Integral Equations 15 (2002), 1409-1434.

[14] I. A. Shishmarev, On a non-linear equation of Sobolev type, Differ. Uravn. 41 (2005); English transl. in Differ. Equ. 41 (2005).

[15] R. E. SHOWALTER, Monotone operators in Banach space and nonlinear partial differential equations, Mathematical Surveys and Monographs, No. 49, Amer. Math. Soc., Providence, RI 1997.

[16] U. Stefanelli, On a class of doubly nonlinear nonlocal evolution equations, J. Differential Integral Equations 15 (2002), 897-922. 
[17] S. L. Sobolev, On a new problem of mathematical physics, Izv. Akad. Nauk SSSR Ser. Mat. 18: 1 (1954), 3-50.

[18] G. A. SVIRIDYUK AND V. E. Fedorov, Analytic semigroups with kernel and linear equations of Sobolev type, Sibirsk. Mat. Zh. 36 (1995), 1130-1145; English transl., Siberian Math. J. 36 (1995), 973-987.

[19] A. G. Sveshnikov, A. B. Al'shin, M. O. Korpusov and Yu. D. Pletner, Linear and nonlinear equations of Sobolev type, Fizmatlit, Moscow 2007. 